\title{
Colloidal processing of fully stabilized zirconia laminates comprising graphene oxide-enriched layers
}

\author{
Acacio Rincón ${ }^{1}$, Rodrigo Moreno ${ }^{1}$, Carlos Fidel Gutiérrez-González², Raquel \\ Saiz $^{3}$, María Dolores Salvador ${ }^{4}$, Amparo Borrell ${ }^{4 *}$
}

${ }^{1}$ Instituto de Cerámica y Vidrio (ICV), Consejo Superior de Investigaciones Científicas (CSIC), Kelsen 5, E-28049 Madrid, Spain

${ }^{2}$ Centro de Investigación en Nanomateriales y Nanotecnología (Consejo Superior de Investigaciones Científicas, Universidad de Oviedo, Principado de Asturias), Avenida de la Vega 4-6, 33940 El Entrego, Spain

${ }^{3}$ Nanoinnova Technologies SL, Parque Científico de Madrid. Faraday,7, E28049 Madrid, Spain.

${ }^{4}$ Instituto de Tecnología de Materiales (ITM), Universitat Politècnica de València (UPV), Camino de Vera s/n, 46022 Valencia, Spain

\begin{abstract}
*Corresponding autor: Instituto de Tecnología de Materiales (ITM), Universitat Politècnica de València (UPV), Camino de Vera s/n, 46022 Valencia, Spain. Tel.: +34963877007; Fax: +34963 877629. E-mail: aborrell@upv.es (A. Borrell)
\end{abstract}

\begin{abstract}
Multilayer materials have demonstrated to provide an efficient mechanism for toughening by deflection of a propagating crack by weak interlayers. Therefore, the aim of this work is to study the colloidal processing of $8 \mathrm{~mol} \%$ yttria stabilized zirconia (8YSZ) based laminates by intercalating thin layers of
\end{abstract}


graphene enriched with 8YSZ, and to evaluate the advantages of such multilayered structure in the propagation of cracks induced by indentation. Green tapes of 8YSZ and graphene-oxide with YSZ were obtained by aqueous tape casting and sintered in one-step by spark plasma sintering at $1400{ }^{\circ} \mathrm{C}$. Microindentation results showed that the indentation cracks propagate within the horizontal direction within the ceramic layer, but in the cross-sectional direction the presence of the GO-rich layers stops the cracks without deflection or bifurcation. The hardness and elastic modulus values were higher than 17.6 $\mathrm{GPa}$ and $230 \mathrm{GPa}$, respectively, and similar for all layers.

Keywords: Colloidal processing; 8YSZ; Graphene; Functional properties; Spark plasma sintering

\section{Introduction}

$8 \mathrm{~mol} \%$ yttria stabilized zirconia (8YSZ) has been extensively used as an electrolyte because of its low electronic and high oxide ion conductivity over wide ranges of temperature and oxygen partial pressure, as well as excellent chemical stability under reduced and oxidized atmospheres at a high temperature. These properties make 8YSZ a powerful material for applications as oxygen sensors and solid oxide fuel cells [1-5]. The basic structure of a solid oxide fuel cell (SOFC) comprises at least three layers of ceramics or cermet: i.e., electrolyte, anode and cathode layers [6,7]. The electrolyte is a dense ceramic, typically yttria stabilized zirconia (YSZ) or gadolinium doped ceria (CGO), whereas the electrodes must be porous and can be either a ceramic or a cermet. Typical anode materials are Ni-YSZ and Ni-CGO while LSM (La, Sr, 
Mn oxide)-YSZ and LSCF (La, Sr, Co, Fe oxide) are the most frequently used as cathode materials [8-10]. The most important designs for SOFCs include tubular and planar configurations [11,12]. Among them, the anode-supported planar configuration is probably the most extensively used. Planar cells are fabricated by considering the different layers (electrode and electrolytes) produced by different techniques, such as tape casting and screen printing, which are the most suitable to produce large surfaces and fast, low cost mass production. Because of the multi-layer nature of the cells, any mismatch in the free sintering kinetics of the individual layers leads to stress and distortion during the sintering process [13-15]. Hence, the electrolyte layer must have high fracture strength and toughness, good thermal conductivity and a thermal expansion coefficient similar to that of the other components. Fully stabilized zirconia has not the excellent mechanical properties that partially stabilized zirconia has so that the development of strengthening mechanisms is strongly desired to meet the requirements of SOFCs.

The main reinforcing mechanisms for zirconia ceramics are those based on the phase transformation of zirconia from tetragonal to monoclinic induced by mechanical stresses, and the use of composites with second phase particles, whiskers, platelets or fibers and, more recently, the development of ceramic matrix nanocomposites is receiving great attention [16-19]. The use of such nanocomposites has shown to significantly enhance the mechanical properties even at high temperatures. For example, the fracture strength and creep resistance of $\mathrm{Al}_{2} \mathrm{O}_{3}$ were improved by 3 to 5 times and by 3 to 4 orders, respectively, by incorporating only 5\% nano-sized SiC particles [20]. 
Another route for reinforcing the properties of ceramics that is receiving 
found that the hardness decreased with the introduction of GPLs as a minor phase.

An effective way for enhancing the properties of ceramic-based composites is to produce laminates with tailored distribution and thickness of the layers. Multilayer materials have demonstrated to provide an efficient mechanism for toughening by either the deflection of a propagating crack by weak interlayers or by designing strongly joined interfaces where an alternate tensile-compressive residual stress state may arise during cooling from sintering. A broad body of work has been published concerning the processing, sintering, and mechanical performance of zirconia-toughened laminates focusing the key role of the residual stresses on the fracture behavior [32-36].

Colloidal processing allows to obtain uniform dispersion of different phases with high reliability and through simple processing methods $[37,38]$. In particular, great effort is being developed in order to obtain uniform microstructures with a good dispersion of the nanodispersoids by controlling the colloidal and rheological behavior of the mixtures $[39,40]$. In previous works, the preparation of $\mathrm{Al}_{2} \mathrm{O}_{3}-3 \mathrm{YTZP}$-graphene multilayer materials combining tape casting and fast spark plasma sintering technique with good cohesion between layers and high hardness and Young's modulus values has been reported [4143].

However, the processing, sintering and mechanical properties of fully stabilized zirconia (8YSZ) reinforced with carbon derivatives have not been studied in detail. In this case the preparation of laminates containing GO could be an attractive route to introduce weak interfaces capable to reduce the 
residual stresses and to improve the mechanical resistance of the stack in the cells. The aim of this work is to study the colloidal processing of 8YSZ-based laminates by intercalating thin layers of GO-enriched with $8 \mathrm{YSZ}$, and to evaluate the advantages of such multilayered structure in the propagation of cracks induced by indentation.

\section{Experimental Procedure}

A commercial $\mathrm{ZrO}_{2}$ stabilized with 8 mol\% $\mathrm{Y}_{2} \mathrm{O}_{3}$ (YSZ, TZ-8YS Tosoh, Japan) with mean particle size of $0.4 \mu \mathrm{m}$, surface area of $4.7 \mathrm{~m}^{2} \cdot \mathrm{g}^{-1}$ and density of $5.9 \mathrm{~g} \cdot \mathrm{cm}^{-3}$, and monolayers graphene oxide (Nanoinnova Technologies, Spain), simply referred to as GO, with average lengths and thicknesses in the range of 1 to $4 \mu \mathrm{m}$ and 0.7 to $1.2 \mathrm{~nm}$, respectively, density of $2.0 \mathrm{~g} \cdot \mathrm{cm}^{-3}$ and surface area of $\sim 103 \mathrm{~m}^{2} \cdot \mathrm{g}^{-1}$ were used as starting materials.

The substrates to be coated were prepared by tape casting using an 8YSZ aqueous suspension prepared to a solids loading of 45 vol\% (83 wt\%). The suspension was prepared by mechanical mixing of the ceramic powders in deionized water containing an ammonium salt of poly(acrylic acid), PAA (Duramax D3005, Rohm \& Haas, USA) available as a 35 wt\% aqueous solution. This deflocculant was added in a concentration of $0.5 \mathrm{wt} \%$ in relation to the zirconia powder to provide electrosteric stabilization.

To achieve an optimal dispersion state, different sonication times were applied for periods of 1 min using an ultrasounds probe (UP400S, Dr. Hielscher $\mathrm{GmbH}$, Germany). The suspensions were prepared in a beaker cooled in an ice-water bath to avoid excessive heating during sonication. The rheological behavior of the suspensions was studied after different sonication times, with a 
rotational rheometer (MARS, Thermo-Haake, Germany) using a doublecone/plate geometry as the measuring system. Flow curves were performed by changing shear rate between 0 and $1000 \mathrm{~s}^{-1}$ for $5 \mathrm{~min}$ for the up and down ramps, and the dwell time at the maximum shear rate was $1 \mathrm{~min}$. Temperature was maintained constant at $25{ }^{\circ} \mathrm{C}$. Thixotropy values were calculated by the software of the equipment as the are closed between the up-ramp and the down-ramp of the flow curves. Regression analyses were performed considering only the up-curves of the corresponding rheograms since in the down-curve the behavior changes as a consequence of shearing.

The suspension exhibiting the best rheological behavior was selected for tape casting after adding an acrylic latex emulsion with a content of active matter of 55 wt\% (Duramax B-1000, Rohm \& Haas, PA, USA), which was used as a binder. It was added in concentrations of $5,10,15$ and $20 \mathrm{wt} \%$ related to the total solids content of the suspension, and a defoamer (KS 1115, Zschimmer \& Schwarz, Germany) was also added in a concentration of 0.15 wt\% to allow the elimination of air bubbles originated during homogenization. The so-prepared mixtures were kept under mechanical stirring for 20 min to achieve homogenization before the rheological characterization and casting.

Tape casting was conducted onto a Mylar film using a single blade geometry casting head; the blade height was set at $200 \mu \mathrm{m}$ with a casting speed of $50 \mathrm{~mm} \cdot \mathrm{s}^{-1}$. The tapes were dried $24 \mathrm{~h}$ at room temperature without airflow, and then the green tapes were cut, removed from the support and subjected to eye inspection. A tape was considered satisfactory if it was flawless (i.e., free from holes, cracks and other defects), easily removable from the Mylar carrier film without release, and easily processed after removal. The 
green densities were calculated by a geometric method punching discs of $2 \mathrm{~cm}$ in diameter and measuring their thickness with a digital touch-probe.

The aqueous slurries used for the preparation of the coatings by dipping were prepared to a solids content of $10 \mathrm{wt} \%$ with a volume ratio of $8 Y S Z$ to GO of $30 / 70$. The mixtures were prepared by dispersing first GO in water adding 1 wt\% (with regard to the GO content) of PAA as dispersant, then 2 min of sonication were applied for consecutive periods of $1 \mathrm{~min}$ and further stirring. Later, the PAA deflocculant required to stabilize the zirconia was added to a concentration of $0.5 \mathrm{wt} \%$ (with regard to dry zirconia) prior to the addition of the zirconia powders. Suspensions maintained under mechanical agitation for 15 min were then used for rheological characterization following the same protocol as before. The mass per unit area was calculated by direct weighing and measurement of the deposited area after drying, considering linear edges (trapezoid or square when it applies). The wet edge at the bottom was dried with paper just after dipping. This is a rough measurement and the error is large, but this is a systematic error that would not determine the trend in the experimental series of tests. The thickness usually increases with withdrawal rate for sol-gel solutions but in the case of suspensions thicknesses are much larger and the behavior depends on other parameters, like solids loading, viscosity, particles rearrangement and the possible filtration along the deposited layer as it is a porous medium.

The preparation of the multilaminates was performed according to the flow chart shown in Figure 1. Firstly, coatings were prepared using green 8YSZ tapes of $2.5 \times 3 \mathrm{~cm}^{2}$ as substrates for dipping into the GO/8YSZ suspension using withdrawal rates ranging from 3 to $30 \mathrm{~mm} \cdot \mathrm{s}^{-1}$ and soaking times of 0,60 , 
120,180 , and $300 \mathrm{~s}(0,1,2,3$, and $5 \mathrm{~min})$. As-prepared coatings were left to dry at room conditions for $24 \mathrm{~h}$ before weighing. Two types of laminates were prepared consisting of 3 and 5 layers alternating coated tapes with uncoated ones. These configurations were selected to provide the minimum thickness required for a successful sintering by SPS, and a symmetric structure was designed to avoid possible distortion of the compact as a consequence of thermal mismatch. Another possibility would be to increase significantly the thickness of the layers but this probably would not provide the same reinforcing effect as the cracks would have more distance to propagate. To achieve the correct joining of the green tapes, the uncoated ones were immersed in water and dried slightly, so the deposited water serves as bonding agent between the tapes avoiding the cracking of the dipping layer that occurs when too much water is at the surface or it is not uniformly distributed. A small pressure was applied and discs of $2 \mathrm{~cm}$ in diameter were punched to obtain the stacks. Finally to obtain the sintered material, four stacks of the five tapes conformation and five of the three-tape conformation were introduced into a 20 -mm-diameter graphite die.

The stacks were sintered using a Spark Plasma Sintering device, SPS HP D25/1 (FCT Systeme GmbH, Rauenstein, Germany) at a temperature of $1400 \stackrel{\circ}{\circ} \mathrm{C}$ and $80 \mathrm{MPa}$ of pressure to obtain fully sintered bulk materials. The tests were carried out under vacuum at a heating rate of $100 \stackrel{\circ}{\circ} \mathrm{C} \cdot \mathrm{min}^{-1}$ with a 3 min dwelling time at the maximum temperature.

Densification of the sintered samples was evaluated in terms of relative density and has been determined by Archimedes' method, following ASTM-C373 Standard. Mechanical properties were evaluated via micro and nano- 
indentation techniques. $\mathrm{K}_{\mathrm{IC}}$ values were studied by the cracks induced by applying loads of $2 \mathrm{~kg}$ with an image analysis program. Hardness $(H)$ and Young's modulus $(E)$ were analysed by a nanoindenter G-200 of Agilent Technol. (Inc., Santa Clara, CA) under a $1200 \mathrm{~nm}$ constant indentation depth program. A Berkovich tip was used after calibration of the function area in fused silica. Stiffness was recorded in depth by Continuous Stiffness Measurement (CSM). The Poisson's coefficient was 0.23 for all calculations considering a fully dense material.

Sintered samples were fractured on their cross-section and were polished to $0,25 \mu \mathrm{m}$ using SiC paper and diamond suspension. Resulting layers were observed with an optical microscope Nikon LV-100 under bright field illumination. The fracture surface was analysed by using a field emission gun scanning electron microscope (FE-SEM, HITACHI S-4800, SCSIE of the University of Valencia).

\section{Results and discussion}

The zeta potential behaviour of the commercial 8YSZ powder employed in this work has been studied in previous work [44], the isoelectric point being reported to occur at $\mathrm{pH}$ 5.2. In that work it was demonstrated that the addition of a polyelectrolyte shifted down the isoelectric point. Hence, the concentrated 8YSZ suspensions used in this work were prepared in water with the addition of 0.5 wt\% of PAA in relation of the zirconia powders to a solids loading of $45 \mathrm{vol} \%$ (83 wt\%) and homogenized with an ultrasounds probe. To optimize the rheological behavior the effect of sonication time was studied by applying consecutive treatments of $1 \mathrm{~min}$ and measuring the rheological behavior after 
everyone. The flow curves obtained for the applied sonication times are plotted in Figure 2a. The flow curves of the different suspensions were analysed considering different regression models, the best results being obtained for the Herschel-Bulkley model (eq. 1), according to which the shear stress $(\sigma)$ is given by the sum of a yield stress $\left(\sigma_{0}\right)$ and a factor of shear rate $(\dot{\gamma})$ :

$$
\sigma=\sigma_{0}+K \dot{\gamma}^{n}
$$

being $\mathrm{K}$ and $\mathrm{n}$ are constants referred to as consistency factor and flow index, respectively. The data obtained after fitting to that model are shown in Table 1. The calculated values of thixotropy are also given in the table, as well as the viscosities at two representative shear rates, such as $100 \mathrm{~s}^{-1}$ and $500 \mathrm{~s}^{-1}$. The first is the evaluated shear suffering the suspensions through the blade during tape casting. The second is interesting to know the viscosity under strong shearing. From the values shown in the Table 1, it can be observed that the suspension prepared just by mechanical agitation (before sonication) presents a broad thixotropic cycle and a small yield stress that indicate that the particles are not well dispersed. When sonication is applied to the suspension the thixotropic cycle becomes smaller and the viscosity decreases, also. It is also worthy to note that fitting was excellent in all cases with regression indexes as high as $0.9992-0.9999$. Thereby the optimum dispersion was obtained after the application of 5 min of sonication, which led to very low viscosity, slightly shear thinning behavior, desired for most ceramic processing operations, and very small thixotropy. This suspension has also the lowest yield stress. The application of further sonication leads to a loss of stability of the suspension increasing both the viscosity and the thixotropy. Hence, the suspension used for tape casting was prepared after applying 5 min of sonication in consecutive 
periods of $1 \mathrm{~min}$ separated by $10 \mathrm{~min}$ of low speed mixing with helices, and the addition of the suitable additives.

Once the dispersing conditions were optimized the effect of binder addition of the casting suspension on the rheology was studied. Figure $2 \mathrm{~b}$ shows the flow curves obtained after the addition of an acrylic latex binder in concentrations of $5,10,15$ and 20 wt\% with regard to dry solids. The results of the regression analyses are also shown in Table 1. The curves exhibit the shear thinning behavior desired for tape casting and the viscosity of the suspensions decreases with increasing binder contents, because it is accomplished by a decrease in the solids loading because the binder is an aqueous emulsion with an active matter content of $55 \%$.

These suspensions were cast maintaining a blade height of $200 \mu \mathrm{m}$ and a casting speed of $50 \mathrm{~mm} \cdot \mathrm{s}^{-1}$. It was noticed that in. Some cracks appeared in the tape obtained after the addition of $5 \%$ binder because the amount of binder added is not enough to maintain the cohesion among the ceramic particles, whereas the addition of binder in higher proportions led to flexible tapes without macroscopic defects such as bubbles or cracks. The most suitable tape for the subsequent coating and lamination was that obtained after the addition of 10 wt\% of binder, since higher contents decreased the viscosity and thixotropy below the desirable limits and an excess of binder content can difficult burning out. The thickness of the green tapes was $163 \pm 14 \mu \mathrm{m}$. The green density of the tapes was $3.07 \pm 0.08 \mathrm{~g} \cdot \mathrm{cm}^{3}$ which represents a $52 \%$ of the theoretical density being very promising results for the preparation of dense electrolytes.

The suspension of GO/8YSZ employed for the preparation of the thin intermediate layers by dipping contains the low solid content necessary to allow 
an adequate immersion and a proper adherence with the tape cast green substrate. Figure 3 shows the rheological behavior of the dipping layer suspension as prepared and after the application of sonication for $1 \mathrm{~min}$. Although sonication tends to slightly increase the viscosity it was applied to achieve a good dispersion of the powders and to assure its stability during the preparation of the coatings. The rheological parameters after fitting to the Herschley-Bulkley model, and thixotropy and viscosities are also shown in Table 1.

Dipping tests were performed by at constant withdrawal rates between 3 and $30 \mathrm{~mm} \cdot \mathrm{s}^{-1}$. The variation of the deposit mass per unit area with the withdrawal rate of the green $8 \mathrm{YSZ}$ substrate immersion into the GO/8YSZ suspension is plotted in Figure 4, which shows that the deposited mass does not have a clear dependence with the withdrawal rate, but the coating homogeneity is lower when it is deposited at a low speed, so that a withdrawal rate of $4 \mathrm{~mm} \cdot \mathrm{s}^{-1}$ was chosen as optimum for further experiments.

Since dipping is performed using suspensions and green tapes with a high porosity it can be expected that some filtration of the suspension by the porosity channels of the tape could take place, and hence the soaking time can have a direct influence on the deposited mass, as reported elsewhere [45]. Figure 5 shows the mass per unit area of dry coatings prepared by immersion of the tapes in the dipping suspension for different soaking times at a withdrawal rate of $4 \mathrm{~mm} \cdot \mathrm{s}^{-1}$. It is observed that in this case the coating thickness increases with the soaking time until a limit is achieved for times longer than $180 \mathrm{~s}$. Considering that all substrates have a similar green density, the larger thickness obtained for larger soaking times suggests that there exists a time depending 
interaction between the slurry and the substrate, because no filtration takes place with saturated wet substrates. The deposits appear very homogeneous and considering the mass per unit area evolution, those obtained after $5 \mathrm{~min}$ soaking time were selected as this time assured that the maximum growth is reached.

Coated and uncoated tapes were laminated together to produce the multilayer samples as explained in the experimental section and sintered by SPS under the described conditions. Figure $6 a$ shows a general view of the microstructure of the laminate, showing the different alternating layers of 8YSZ (grey layers) and GO/8YSZ (black layers). A detail of one of such GO-enriched layers is shown in Figure 6b. The final thickness of the 8YSZ layers is $\sim 160-180$ $\mu \mathrm{m}$ and the GO/8YSZ layer is approximately $8 \mu \mathrm{m}$ thick. The thickest layers observed in the middle and at the bottom correspond to two joined 8YSZ layers of two different stacks. In spite of the presence of some residual bubbles retained in the tapes, the obtained materials show good properties, such as a Vickers hardness of $17.6 \mathrm{GPa}$ and elastic modulus of $230 \mathrm{GPa}$. These properties of layers were determined by microhardness measurements and by nanoindentation technique.

The nanomechanical properties were investigated along all the width of the laminate in order to detect possible gradients in densification. Figure $7 \mathrm{a}$ shows several arrays of Berkovich imprints performed at a constant $1200 \mathrm{~nm}$ depth-by nanoindentation technique. Figure $7 \mathrm{~b}$ shows the values of the nanohardness and the elastic modulus profiles for indentations. In this figure, the scatter and the indent position have been taken into account in the treatment of the data. The values affected by pores or other defects have been 
eliminated. These curves demonstrate that the density along the cross-section of the sample is constant and the mechanical properties remain constant inside the entire sample, without any differences at the various layers comprising the laminate.

The microstructure of the fracture surfaces of the different layers (8YSZ and GO/8YSZ) in the laminate can be observed in Figure 8. FE-SEM observations of these fracture surfaces show a high degree of densification ( $\sim 98 \%$ of the T.D. estimated considering the thickness of each layer and its density evaluated with the mixtures rule) without apparent macroscopic defects but with some residual porosity. In Figure 8a, it can be observed the end zone of the composite in order to see the layers together and so, analyze the joining of the interfaces. The laminate shows that the cohesion between different layers is very good. It is possible to see the graphite platelets in the GO/8YSZ layer. As observed in Figure $8 \mathrm{~b}$ the $8 \mathrm{YSZ}$ grains size are about $0.6 \mu \mathrm{m}$ and are obtained in any of the layers. These images corroborate that the conditions employed for the SPS procedure were adequate. It must be remarked that the laminated material displays high hardness and elastic modules values mechanical properties that can be explained by the high densification and small grain size achieved by tapes lamination and further non-conventional sintering by SPS technique.

Figure 9 shows two representative pictures of indentations performed on 8YSZ layers. Figure 9a shows four indentations made with different load, the upper cracks have been made with $1 \mathrm{~kg}$ and lower cracks have been made with $2 \mathrm{~kg}$. Figure $9 \mathrm{~b}$ show a detail of one indentation in an 8YSZ layer. As it is clearly observed the indentation cracks propagate in the horizontal direction within the 
ceramic layer but in the cross-sectional direction, the presence of the GO-rich layers causes the crack arrest without deflection or bifurcation. Therefore, it is found that the GO-rich layers of laminate reduce the probabilities of crack generation and propagation, whereas increase the reinforcing or toughening in the laminate. It has been possible to observe that in fact this GO-rich layer introduces weak interfaces capable to reduce the residual stresses and improve the mechanical resistance of the material. The residual stresses developed in a laminate depend on the properties of the constituent layers, the structure of the laminate, the processing methods and the characteristics of the interfaces. Layers with lower CTE or expansive phase transformations or reactions will develop compressive stresses while the adjacent layers will develop tensile stresses [46].

The layered ceramic is considered to be in a stress-free state at the sintering temperature due to the relief of stress by mass transport mechanisms. During cooling from sintering, if the layers are not strongly joined the material will delaminate and each layer will shrink freely to a determined length. On the contrary, if the layers are strongly joined constraint of each layer by its surrounding will result in the generation of residual stresses within the laminate. In this work, the use of sintering by SPS, where the heating and cooling is very fast, and with an applied pressure of $80 \mathrm{MPa}$, the layers are strongly joined and therefore the generation of residual stresses occur within the laminate.

The study of the compressive or tensile stresses within the laminate is very complicated and labor-intensive and therefore at the moment it is out of the scope of this work, which emphasizes processing. 
Some authors have demonstrated improved mechanical properties in the case of $\mathrm{ZrO}_{2} / \mathrm{CNTs}$ composites compared with the monolithic materials $[23,47]$. However, their mechanical properties such as fracture toughness are still not good enough to meet the requirements of certain high performance parts [48]. The most critical problem causing the deleterious effects on mechanical properties after the addition of CNTs or CNFs is the dispersion of this carbon source in the matrix because of the tendency to aggregate into bundles and therefore disperse poorly in the ceramic matrix. Non-uniform dispersion of CNTs or CNFs will result in large defects, poor densification and thus poor load transfer.

As we explained earlier, in the case of GO-YSZ or GPLs-ZTA composites $[30,31]$, the incorporation of graphene into ceramic matrix led to improvement in the fracture toughness but the hardness decreases. In this work for the first time, the effect to the GO-rich layers on the propagating crack in the ceramic laminate is controllable and, therefore, this issue opens the possibilities to design laminate materials with a small grain size, high hardness and high fracture toughness with a tailored distribution and thickness of the layers.

\section{Conclusions}

In the present work, the preparation and characterization of fully dense 8YSZ laminates alternating layers with or without graphene fabricated by colloidal processing and subsequent spark plasma sintering is reported. 8YSZ homogeneous, low-viscosity suspensions without and with the addition of graphene oxide (GO/8YSZ) were prepared to solids loadings up to 45 vol. $\%$ by 
homogenizing the order of addition of the different components and the homogenization time by sonication.

The addition of GO-enriched layer into 8YSZ laminates resulted in an increase of the mechanical behavior, in particular in the fracture toughness. It was found that the GO-rich layers of laminate reduce the probabilities of crack generation and propagation, while increasing the reinforcing or toughening of the bulk laminate. Therefore, it is possible to design materials with controlled microstructure and mechanical properties with a high number of different layers by intercalating thin layers of graphene. The mechanical properties at the different layers of the laminate are rather similar, so that the presence of graphene is not deleterious for the laminate integrity and the layers properties.

\section{Acknowledgements}

This work has been supported by the Spanish Ministry of Economy and Competitiveness (project MAT2015-67586-C3-R) and the Generalitat Valenciana by the financial support for the GV/2014/009 project. M.D. Salvador thanks to CAPES - Programa Ciências sem Fronteiras (Brazil) for the concession of a PVE project № A086/2013. A. Borrell, acknowledges the Spanish Ministry of Economy and Competitiveness for her Juan de la CiervaIncorporación contract (IJCI-2014-19839).

\section{References}

[1] V.V. Kharton, F.M.B. Marques, A. Atkinson, Transport properties of solid oxide electrolyte ceramics: a brief review, Solid State lonics 174 (2004) 135149. 
[2] M. Mori, T. Abe, H. Itoh, O. Yamamoto, Y. Takeda, T. Kawahara, Cubicstabilized zirconia and alumina composites as electrolytes in planar type solid oxide fuel cells, Solid State lonics 74 (1994) 157-164.

[3] A. Atkinson, S. Barnett, R.J. Gorte, J.T.S. Irvine, A.J. McEvoy, M. Mogensen, S.C. Singhal, J. Vohs, Advanced anodes for high-temperature fuel cells, Nat. Mater. 3 (2004) 17-27.

[4] S.C. Singhal, Science and technology of solid-oxide fuel cells, MRS Bull 25 (3) (1997) 16-21.

[5] J. Will, A. Mitterdorfer, C. Kleinlogel, D. Perednis, L.J. Gauckler, Fabrication of thin electrolytes for second-generation solid oxide fuel cells, Solids State Ionics 131 (1-2) (2000) 79-96.

[6] N.Q. Minh. Ceramic fuel cells. J. Am. Ceram. Soc. 76 (3) (1993) 563-588.

[7] J.C. Ruiz-Morales, J. Canales-Vázquez, D. Marrero-López, J. PeñaMartínez, D. Pérez-Coll, P. Núñez, J.C. Rodríguez-Placeres, B. BallesterosPérez, V.I. Dorta-Martín, C. Savaniu, Pilas de combustible de óxidos sólidos (SOFC). Santa Cruz de Tenerife: CCPC, 2008.

[8] M.A. Laguna-Bercero, A. Larrea, J.I. Peña, R. Merino, V.M. Orera, Structured porous $\mathrm{Ni}$ and Co-YSZ cermet fabricated from directionally solidified eutectic composites, J. Eur. Ceram. Soc. 25 (2005) 1455-1462.

[9] J.B. Huang, Z.Q. Mao, Z.X. Liu, C. Wang, Performance of fuel cells with proton conducting ceria-based composite electrolyte and nickel-based electrodes, J. Power Sources 175 (2008) 238-243.

[10] Y.M. Park, J.H. Kim, H. Kim, High-performance composite cathodes for solidoxide fuel cells, Int. J. Hydrogen Energy 36 (2011) 9169-9179. 
[11] S.M. Jamil, M.H.D. Othmana, M.A. Rahmana, J. Jaafar, A.F. Ismail, K. Li, Recent fabrication techniques for micro-tubular solid oxide fuel cell support: A review, J. Eur. Ceram. Soc. 35 (2015) 1-22.

[12] S.C..Singhal, Solid oxide fuel cells for stationary, mobile, and military applications, Solid State Ionics 152-153 (2002) 405-410.

[13] R.K. Bordia, A. Jagota, Crack-growth and damage in constrained sintering films, J. Am. Ceram. Soc. 76 (1993) 2475-2485.

[14] R.K. Bordia, R. Raj, Sintering behavior of ceramic films constrained by a rigid substrate, J. Am. Ceram. Soc. 68 (1985) 287-292.

[15] F. Li, J. Pan, O. Guillon, A. Cocks, Predicting sintering deformation of ceramic film constrained by rigid substrate using anisotropic constitutive law, Acta Mater. 58 (2010) 5980-5988.

[16] R.H.K. Hannink, P.M. Kelly, B.C. Muddle, Transformation toughening in zirconia-containing ceramics, J. Am. Ceram. Soc. 83 (3) (2000) 461-487.

[17] D.J. Green, R.H.J. Hannink, M.V. Swain, Transformation toughening of ceramics. CRC Press, Boca Raton, FL, 1989.

[18] A.H. Heuer, Transformation toughening in $\mathrm{ZrO}_{2}$-containing ceramics, J. Am. Ceram. Soc. 70 (10) (1987) 689-698.

[19] W.M. Kriven, Possible alternative transformation toughness to zirconia: crystallographic aspects, J. Am. Ceram. Soc. 71 (12) (1988) 1021-1030.

[20] K. Niihara, A. Nakahira, T. Uchiyama, T. Hirano, High-temperature mechanical properties of $\mathrm{Al}_{2} \mathrm{O}_{3}-\mathrm{SiC}$ composites, In Fracture Mechanics of Ceramics, Vol. 7, ed., R.C. Bradt, A.G. Evans, D.P.H. Hasselman and F.F. Lange. Plenum Press, New York, 1986, pp. 103-116. 
[21] A. Duszová, J. Dusza, K. Tomásek, G. Blugan, J. Kuebler, Microstructure and properties of carbon nanotube/zirconia composite, J. Eur. Ceram. Soc. 28 (5) (2008) 1023-1027.

[22] M. Mazaheri, D. Mari, R. Schaller, G. Bonnefont, G. Fantozzi, Processing of yttria stabilized zirconia reinforced with multi-walled carbon nanotubes with attractive mechanical properties, J. Eur. Ceram. Soc. 31 (2011) 2691-2698.

[23] N.P. Padture, Multifunctional composites of ceramics and single-walled carbon nanotubes, Adv. Mater. 21 (17) (2009) 1767-1770.

[24] J.H. Shin, S.H. Hong, Microstructure and mechanical properties of single wall carbon nanotube reinforced yttria stabilized zirconia ceramics, Solid State lonics 556 (2012) 382-387.

[25] A. Borrell, V.G. Rocha, R. Torrecillas, A. Fernández, Improvement of carbon nanofibers $/ \mathrm{ZrO}_{2}$ composites properties with a zirconia nanocoating on carbon nanofibers by sol-gel method, J. Am. Ceram. Soc. 94 (2011) 2048-2052. [26] E. Zapata-Solvas, D. Gómez-García, A. Domínguez-Rodríguez, Towards physical properties tailoring of carbon nanotubes-reinforced ceramic matrix composites, J. Eur. Ceram. Soc. 32 (2012) 3001-3020.

[27] N. Garmendia, I. Santacruz, R. Moreno, I. Obieta, Slip casting of nanozirconia/MWCNT composites using a heterocoagulation process, J. Eur. Ceram. Soc. 29 (2009) 1939-1945.

[28] R. Poyato, A.L. Vasiliev, N.P. Padture, H. Tanaka, T. Nishimura, Aqueous colloidal processing of single-wall carbon nanotubes and their composites with ceramics, Nanotechnol. 17 (2006) 1770-1777.

[29] M. Poorteman, M. Traianidis, G. Bister, F. Cambier, Colloidal processing, hot pressing and characterisation of electroconductive MWCNT-alumina 
composites with compositions near the percolation threshold, J. Eur. Ceram. Soc. 29 (2009) 669-675.

[30] J.H. Shin, S.H. Hong, Fabrication and properties of reduced graphene oxide reinforced yttria-stabilized zirconia composite ceramics, J. Eur. Ceram. Soc. 34 (2014) 1297-1302.

[31] J. Liu, H. Yan, M.J. Reece, K. Jiang, Toughening of zirconia/alumina composites by the addition of graphene platelets, J. Eur. Ceram. Soc 32 (2012) 4185-4193.

[32] H.M. Chan, Layered ceramics: processing and mechanical behavior, Ann. Rev. Mater. Sci. 27 (1997) 249-282.

[33] D.J. Green, R. Tandon, V.M. Sglavo, Crack arrest and multiple cracking in glass through the use of designed residual stress profiles, Science 283 (5406) (1999) 1295-1297.

[34] D.B. Marshall, J.J. Ratto, F.F. Lange, Enhanced fracture-toughness in layered microcomposites of $\mathrm{Ce}-\mathrm{ZrO}_{2}$ and $\mathrm{Al}_{2} \mathrm{O}_{3}$, J. Am. Ceram. Soc. 74 (12) (1991) 2979-2987.

[35] A.J. Sanchez-Herencia, C. Pascual, J. He, F.F. Lange, $\mathrm{ZrO}_{2} / \mathrm{ZrO}_{2}$ layered composites for crack bifurcation, J. Am. Ceram. Soc. 82 (6) (1999) 1512-1518.

[36] R. Bermejo, C. Baudín, R. Moreno, L. Llanes, A.J. Sánchez-Herencia, Processing optimisation and fracture behaviour of layered ceramic composites with highly compressive layers, Comp. Sci. Technol. 67 (2007) 1930-1938.

[37] R. Moreno, Colloidal processing of ceramics and composites, Adv. Appl. Ceram. 111 (5-6) (2012) 246-253. 
[38] R. Moreno, Colloidal Methods, In Processing of Ceramics and Composites, Bansal NP, Boccaccini AR, ed., John Wiley \& Sons, Inc, Hoboken, NJ (USA), p 147-181, 2012.

[39] M. Poorteman, M. Traianidis, G. Bister, F. Cambier, Colloidal processing, hot pressing and characterisation of electroconductive MWCNT-alumina composites with compositions near the percolation threshold, J. Eur. Ceram. Soc. 29 (2009) 669-675.

[40] V.M. Candelario, F. Guiberteau, R. Moreno, A.L. Ortiz, Aqueous colloidal processing of submicrometric SiC plus $\mathrm{Y}_{3} \mathrm{Al}_{5} \mathrm{O}_{12}$ with diamond nanoparticles, J. Eur. Ceram. Soc. 33 (13-14) (2013) 2473-2482.

[41] A. Rincón, R. Moreno, A.S.A. Chinelatto, C.F. Gutiérrez, M.D. Salvador, A. Borrell, Effect of graphene and CNFs addition on the mechanical and electrical properties of dense alumina-toughened zirconia composites, Ceram. Int. 42 (2016) 1105-1113.

[42] A. Rincón, A.S.A. Chinelatto, R. Moreno, Tape casting of alumina/zirconia suspensions containing graphene oxide, J. Eur. Ceram. Soc. 34 (2014) 18191827.

[43] A. Rincón, R. Moreno, A.S.A. Chinelatto, C.F. Gutiérrez, A. Rayón, M.D. Salvador, A. Borrell, $\mathrm{Al}_{2} \mathrm{O}_{3}-3$ YTZP-Graphene multilayers produced by tape casting and spark plasma sintering, J. Eur. Ceram. Soc. 34 (2014) 2427-2434. [44] L. Gómez, J. Escobar, M.T. Colomer, R. Moreno, Manufacture of YSZ-LSM semi-cell by colloidal processing, Mater. Sci. For. 727-728 (2012) 746-751. [45] J. Gurauskis, Deposition via dip coating technique of dense yttrium stabilized zirconia layers, Int. J. Appl. Ceram. Technol. 10 (2013) 79-86. 
[46] T. Chartier, D. Merle, J.L. Besson, Laminar ceramic composites, J. Eur. Ceram. Soc. 15 (1995) 101-107.

[47] Y. Jian, W. Ting, X. Zhipeng, X. Weijiang, Zirconia-based nanocomposite toughened by functionalized multi-wall carbon nanotubes, J. Alloys Comp. 581 (2013) 452-458.

[48] A. Bravo-Leon, Y. Morikawa, M. Kawahara, M.J. Mayo, Fracture toughness of nanocrystalline tetragonal zirconia with low yttria content, Acta Mater. 50 (18) (2002) 4555-4562. 


\section{Captions to figures:}

Figure 1. Schematic flow chart showing the dip-coating, the stacking, the punching process that allows the conformation of the different architectures and then, the SPS process.

Figure 2. Flow curves of suspensions of $8 Y S Z$ (45 vol\% solids) prepared at different sonication (US) times (a) and of suspensions of 8YSZ after the addition of different amounts of binder in wt\%(b).

Figure 3. Rheological behavior of $10 \mathrm{wt} \%$ solids suspensions of GO/8YSZ prepared at different sonication times.

Figure 4. Variation of mass per unit area for coatings prepared by dipping at different withdrawal rates with 10 wt\% slurry.

Figure 5. Variation of mass per unit area with soaking time for coatings prepared with $10 \mathrm{wt} \%$ slurry at a withdrawal rate of $4 \mathrm{~mm} \cdot \mathrm{s}^{-1}$.

Figure 6. Optical microscopy images of the laminate sintered by SPS (a), and a detail of one of such GO-enriched layer (b).

Figure 7. Optical microscope image acquired on the cross-section of the sample, revealing the Berkovich imprints performed at $1200 \mathrm{~nm}$ (a). Hardness and Young's modulus as a function of the indentation depth obtained by nanoindentation for the laminate (b).

Figure 8. FE-SEM images showing the fracture surfaces of the 8YSZ and GO/8YSZ layers (a), and 8YSZ layer (b).

Figure 9. Optical microscopy images of four indentations performed on 8YSZ layers (a) and a detail of one of indentation in an 8YSZ layer (b). 
Table 1. Rheological parameters of concentrated suspensions (45 vol\% solids) of $8 \mathrm{YSZ}$ as a function of both sonication time (US) and binder content (wt\% B for suspension prepared with 5 ' US), and diluted suspensions (10 wt\%) of mixtures GO-8YSZ.

\begin{tabular}{|c|c|c|c|c|c|c|c|c|}
\hline Suspension & Treatment & $\begin{array}{l}\text { Thixotropy } \\
\qquad(\mathrm{Pa} / \mathrm{s})\end{array}$ & $\begin{array}{c}\eta \\
\left(100 s^{-1}\right)\end{array}$ & $\begin{array}{c}\eta \\
\left(500 s^{-1}\right)\end{array}$ & $\sigma_{0}(\mathrm{~Pa})$ & K & $\mathrm{n}$ & $r$ \\
\hline \multirow[t]{5}{*}{$8 Y S Z$} & $0^{\prime}$ US & 5606 & 212 & 103 & 5.60 & 0.63 & 0.69 & 0.9993 \\
\hline & $2^{\prime}$ US & 7448 & 210 & 92.9 & 0.77 & 2.20 & 0.40 & 0.9998 \\
\hline & $4^{\prime}$ US & 2380 & 147 & 73.1 & 4.53 & 0.31 & 0.75 & 0.9994 \\
\hline & $5^{\prime}$ US & 2506 & 121 & 65.8 & 0.82 & 1.67 & 0.50 & 0.9998 \\
\hline & $6^{\prime}$ US & 3519 & 189 & 98.1 & 3.02 & 0.69 & 0.68 & 0.9999 \\
\hline \multirow{4}{*}{ 8YSZ+Binder } & $5 \% B$ & 2944 & 129 & 68.3 & 0.39 & 0.90 & 0.58 & 0.9992 \\
\hline & $10 \% \mathrm{~B}$ & 2404 & 109 & 59.1 & 0.99 & 0.51 & 0.65 & 0.9998 \\
\hline & $15 \% \mathrm{~B}$ & 1484 & 89.4 & 49.0 & 0.91 & 0.39 & 0.66 & 0.9998 \\
\hline & $20 \%$ B & 778 & 65.3 & 38.6 & 0.74 & 0.22 & 0.72 & 0.9998 \\
\hline \multirow{2}{*}{ GO-8YSZ } & $0^{\prime}$ US & 199 & 3.9 & 2.4 & 0.28 & 0.0003 & 1.31 & 0.9987 \\
\hline & $1^{\prime}$ US & 271 & 6.8 & 3.9 & 0.44 & 0.0008 & 1.21 & 0.9983 \\
\hline
\end{tabular}




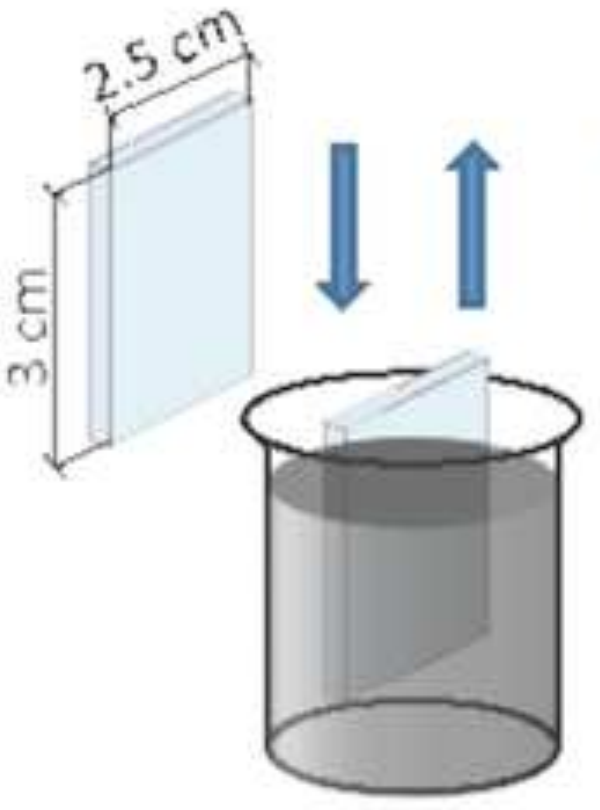

DIPPING

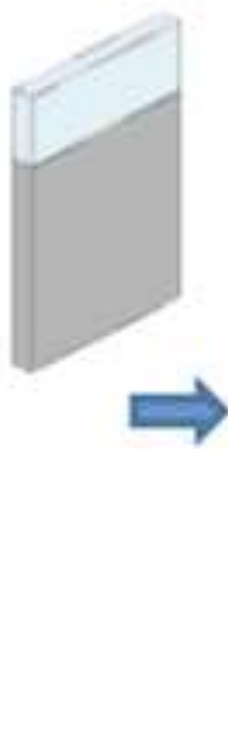

STACKING

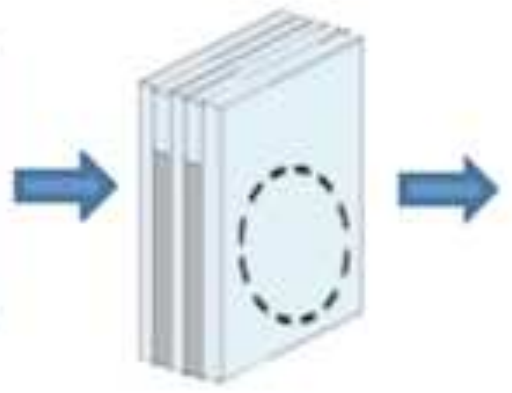

$\Phi=2 \mathrm{~cm}$

PUNCHING

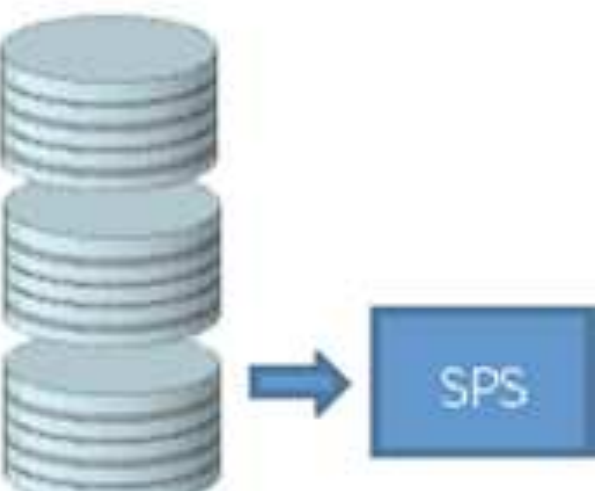

$5 \times 4$

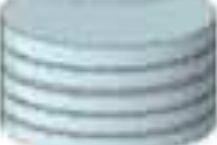


Figure 2

Click here to download high resolution image

a)

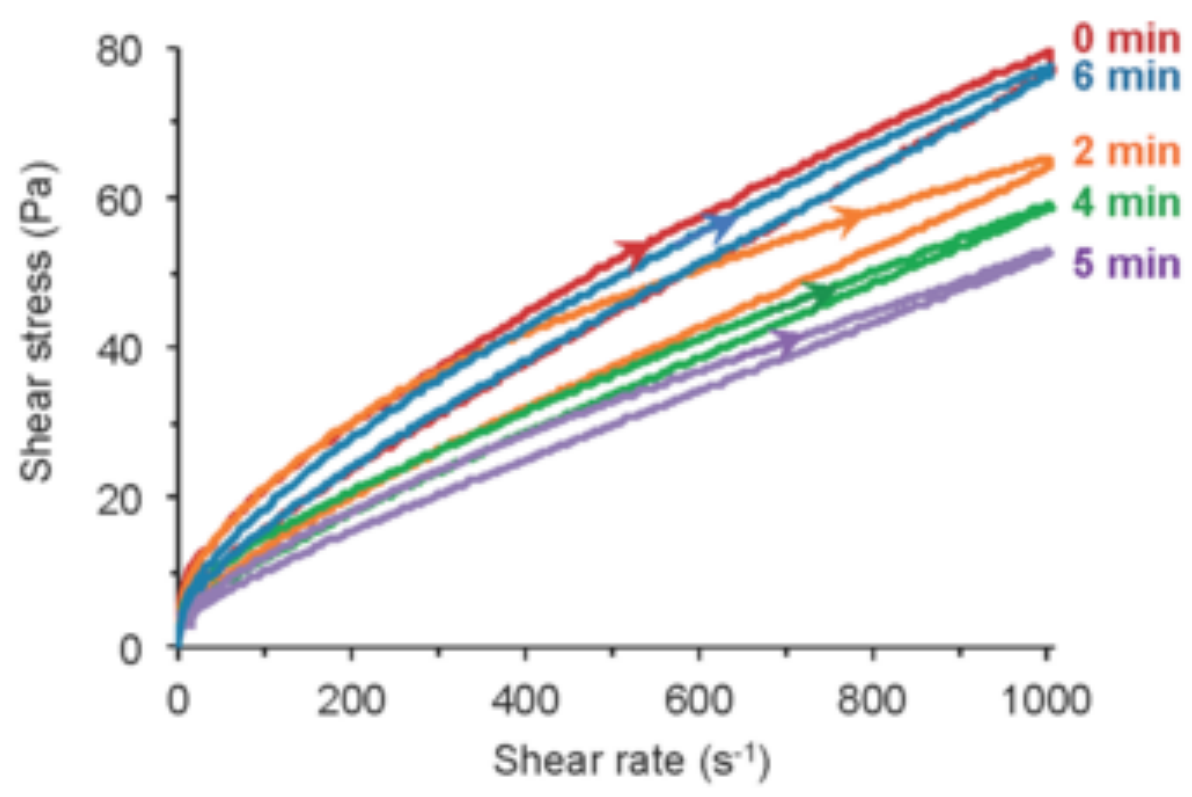

b)

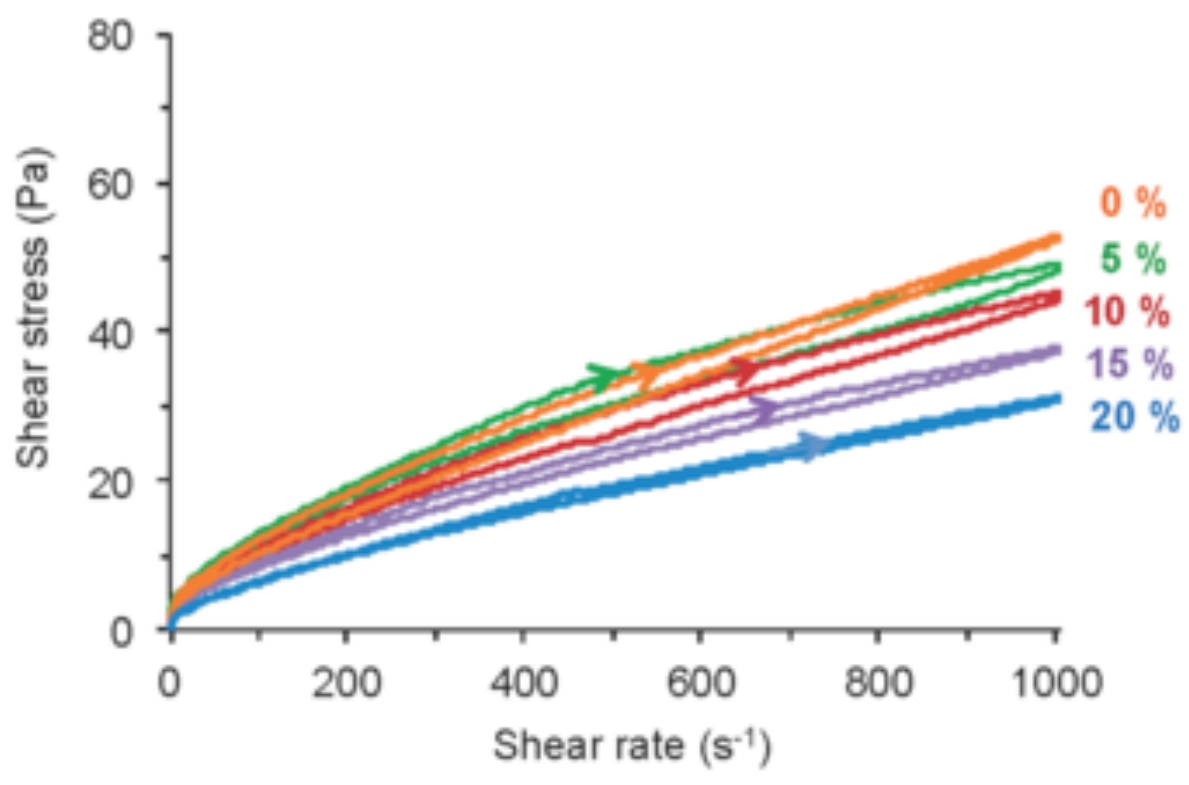


Click here to download high resolution image

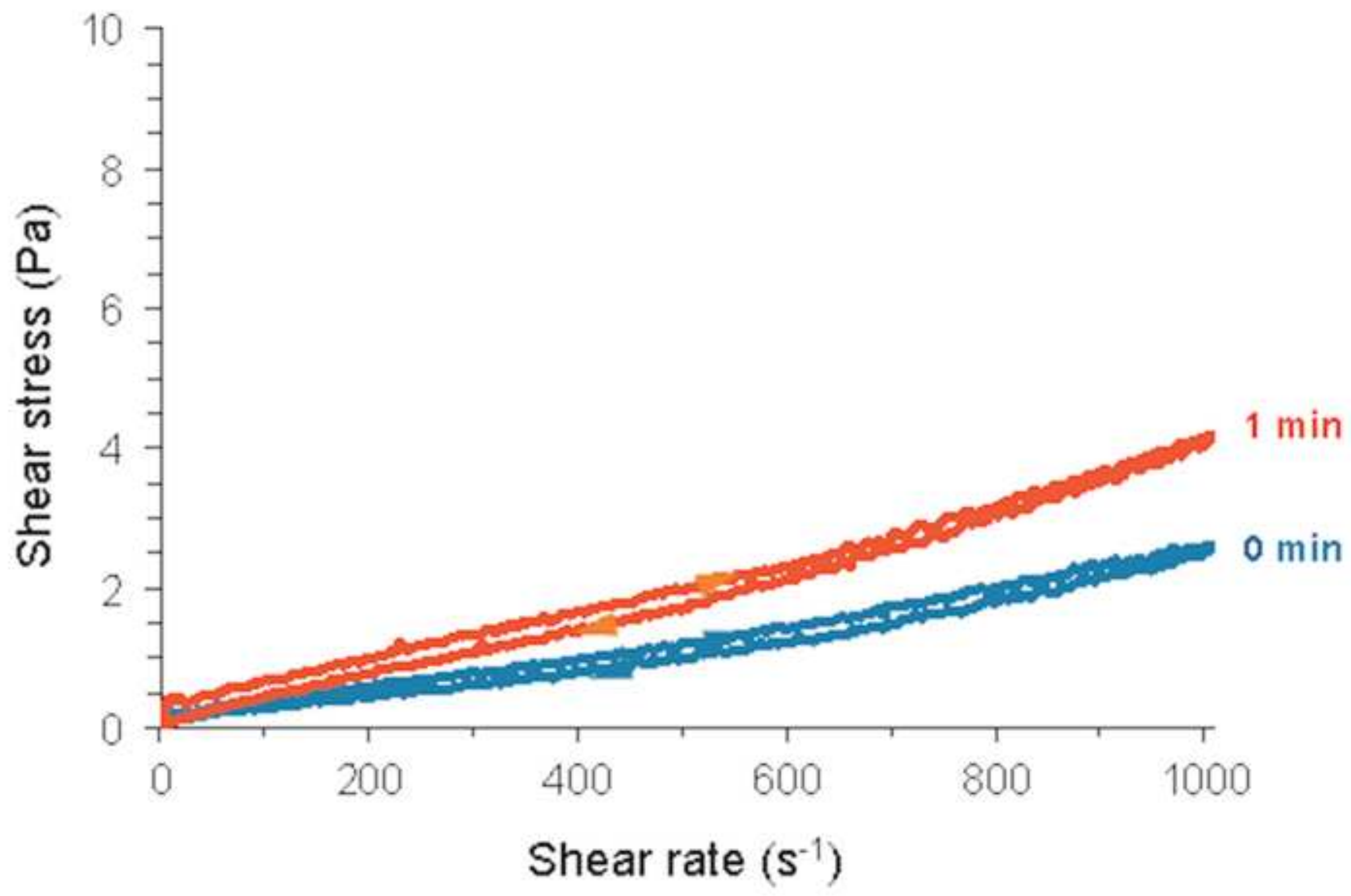




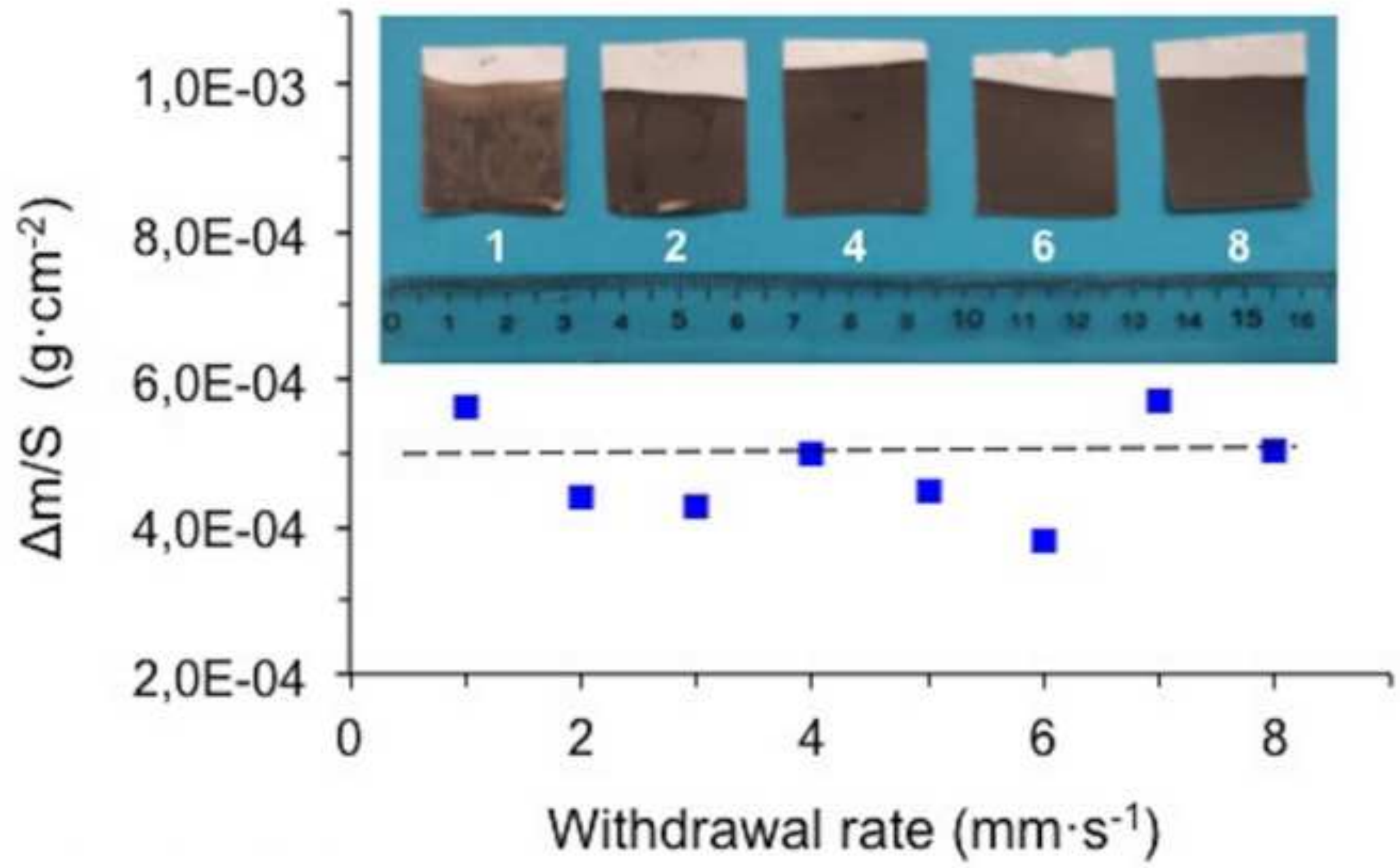




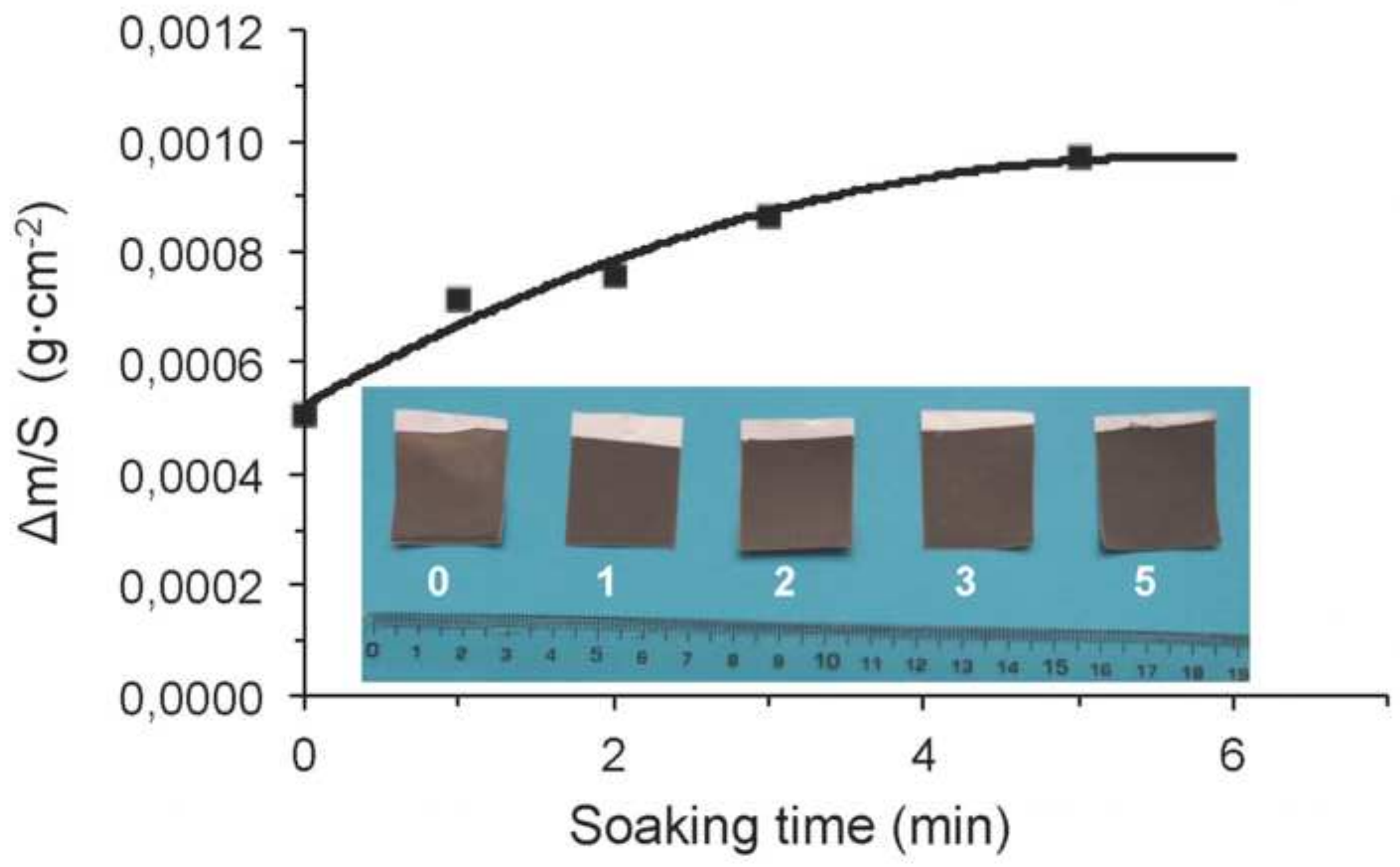


Click here to download high resolution image

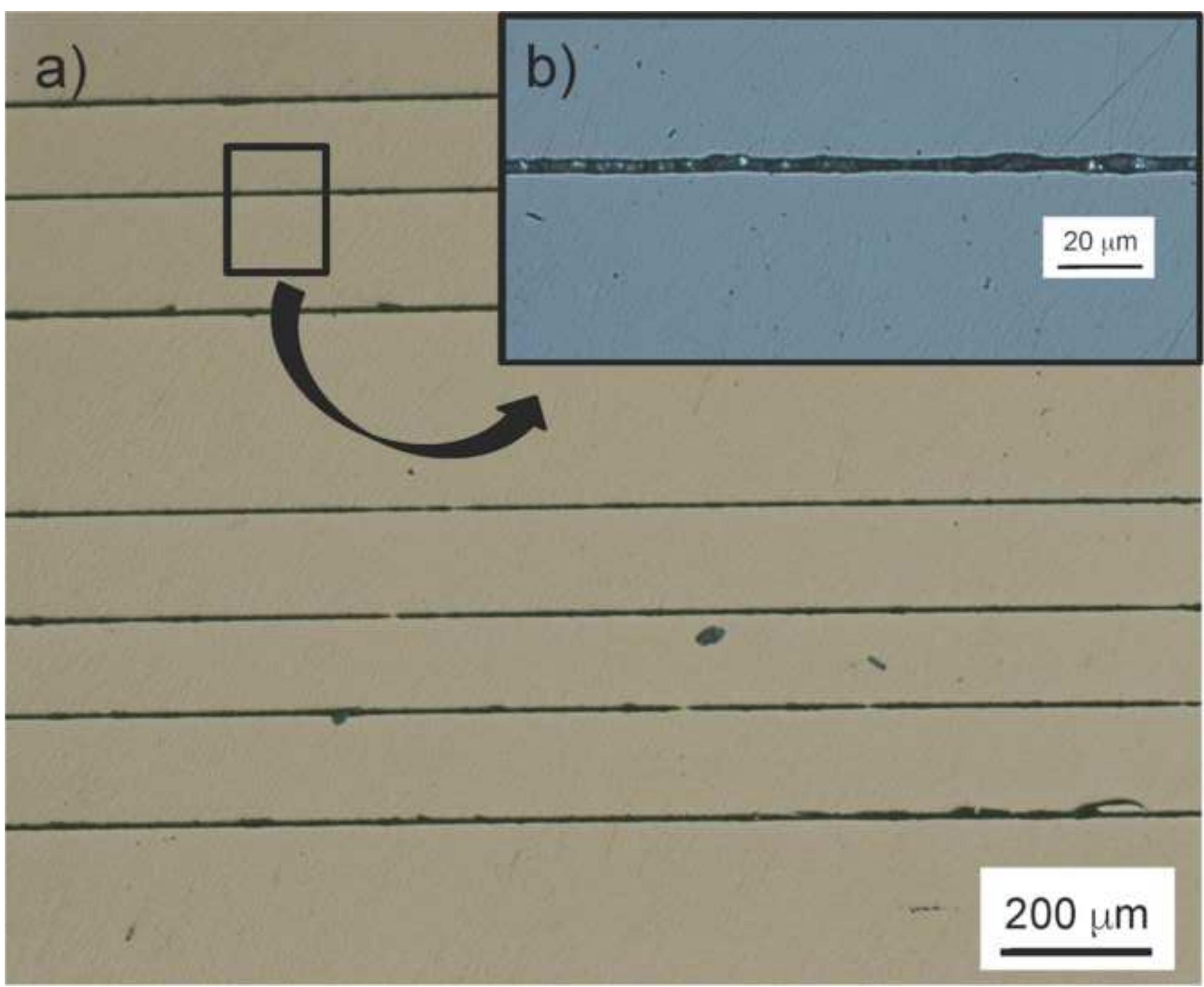


Click here to download high resolution image
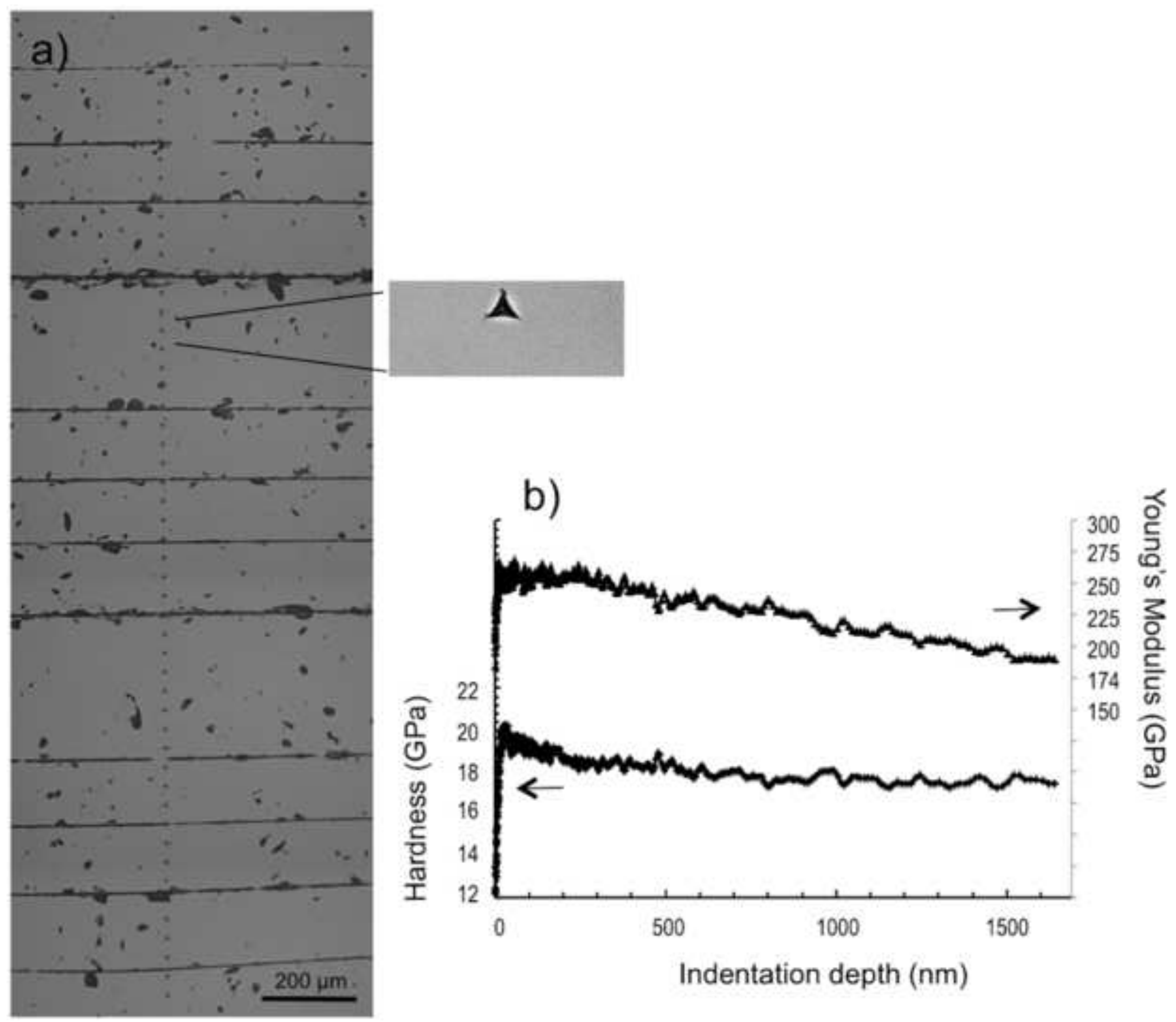
Click here to download high resolution image
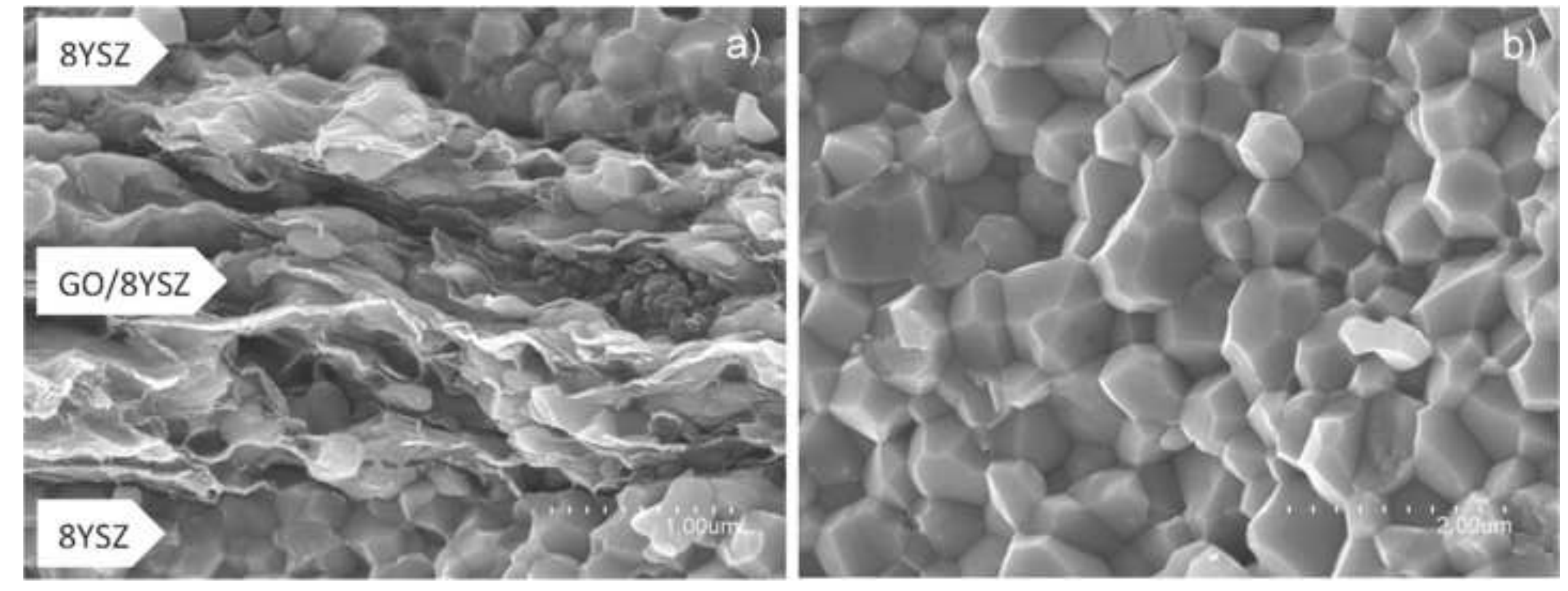
Click here to download high resolution image

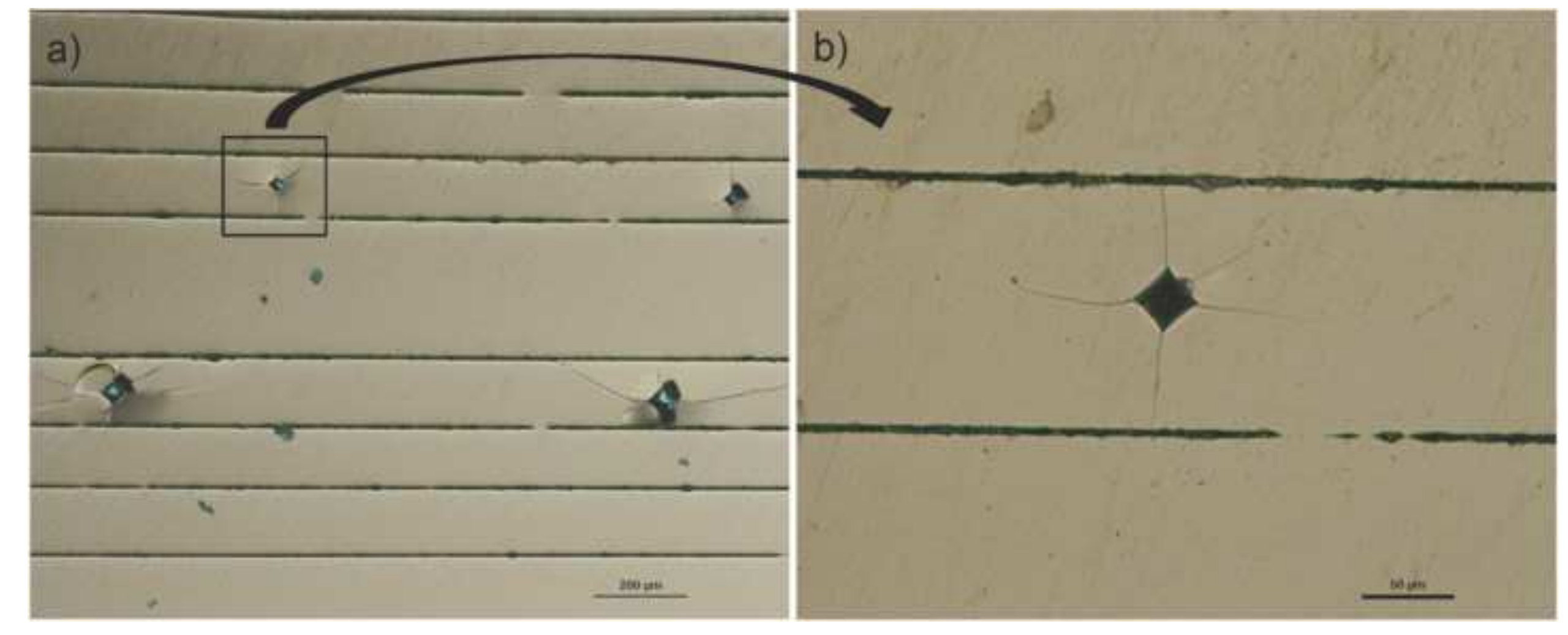




\section{Captions to figures:}

Figure 1. Schematic flow chart showing the dip-coating, the stacking, the punching process that allows the conformation of the different architectures and then, the SPS process.

Figure 2. Flow curves of suspensions of $8 Y S Z$ ( 45 vol\% solids) prepared at different sonication (US) times (a) and of suspensions of 8YSZ after the addition of different amounts of binder in wt\%(b).

Figure 3. Rheological behavior of $10 \mathrm{wt} \%$ solids suspensions of GO/8YSZ prepared at different sonication times.

Figure 4. Variation of mass per unit area for coatings prepared by dipping at different withdrawal rates with $10 \mathrm{wt} \%$ slurry.

Figure 5. Variation of mass per unit area with soaking time for coatings prepared with $10 \mathrm{wt} \%$ slurry at a withdrawal rate of $4 \mathrm{~mm} \cdot \mathrm{s}^{-1}$.

Figure 6. Optical microscopy images of the laminate sintered by SPS (a), and a detail of one of such GO-enriched layer (b).

Figure 7. Optical microscope image acquired on the cross-section of the sample, revealing the Berkovich imprints performed at 1200 nm (a). Hardness and Young's modulus as a function of the indentation depth obtained by nanoindentation for the laminate (b).

Figure 8. FE-SEM images showing the fracture surfaces of the 8YSZ and GO/8YSZ layers (a), and 8YSZ layer (b).

Figure 9. Optical microscopy images of four indentations performed on 8YSZ layers (a) and a detail of one of indentation in an 8YSZ layer (b). 